\title{
Complexities in Prognostication in Advanced Cancer
}

\section{Citation}

Lamont, Elizabeth B., and Nicholas A. Christakis. 2003. "Complexities in Prognostication in Advanced Cancer." JAMA 290 (1) (July 2): 98. doi:10.1001/jama.290.1.98.

\section{Published Version}

doi:10.1001/jama.290.1.98

\section{Permanent link}

http://nrs.harvard.edu/urn-3:HUL.InstRepos:33839956

\section{Terms of Use}

This article was downloaded from Harvard University's DASH repository, and is made available under the terms and conditions applicable to Other Posted Material, as set forth at http:// nrs.harvard.edu/urn-3:HUL.InstRepos:dash.current.terms-of-use\#LAA

\section{Share Your Story}

The Harvard community has made this article openly available.

Please share how this access benefits you. Submit a story.

\section{Accessibility}




\section{Complexities in Prognostication in Advanced Cancer "To Help Them Live Their Lives the Way They Want to"}

Elizabeth B. Lamont, MD, MS

Nicholas A. Christakis, MD, PhD, MPH

\section{THE PATIENT'S STORY}

Ms $\mathrm{M}$ is an 83-year-old, nulliparous woman who lives in her own home with a friend of 50 years' duration. She presented to Dr D on August 2, 1999, with a list of concerns, one of which was a new set of skin lesions on her abdomen. Dr D immediately suspected metastatic cancer and scheduled a fine needle aspiration for that day. The pathological finding was an unusual lipoma.

A couple of weeks later Ms M saw Dr D's nurse practitioner for evaluation of abdominal discomfort; the physical examination findings were normal other than the skin lesions. Three weeks later, she was admitted to the hospital with abdominal pain, nausea, and vomiting and was found to have an infiltrative narrowing of the colon, from the cecum to the mid transverse colon. Biopsy results showed adenocarcinoma in a single-cell infiltrative pattern suggestive of gastric origin. The partial bowel obstruction resolved clinically, and she went home with a plan to keep stools loose to prevent recurrence of obstruction. The patient and physician had a thorough discussion of chemotherapy vs comfort-oriented therapy. The patient was inclined toward comfort care, but she felt she should "do something" because she feared her many caring relatives would "have regrets" if she did not. On a hunch, Dr D asked the pathologist to look for estrogen receptors in the biopsy specimen given the uncertainty of the primary tumor (even though the findings of the breast examination and mammogram were both normal). Interestingly the cells were $40 \%$ estrogen-receptor positive, so, as an alternative to chemotherapy, Dr D offered her an empirical trial of tamoxifen, which Ms M accepted with some relief at escaping chemotherapy. At that time, Dr D told Ms M that she thought her prognosis was on the order of months; she estimated that Ms M would probably die by Christmas. To Dr D's surprise, Ms M stabilized despite some initial weight loss, and the lesions on her abdomen shrank and disappeared.

\section{CME course available at jama.com}

Predicting survival and disclosing the prediction to patients with advanced disease, particularly cancer, is among the most difficult tasks that physicians face. With the deemphasis of prognosis in favor of diagnosis and therapeutics in the medical literature, physicians may have difficulty finding the survival information they need to make appropriate estimates of survival for patients who develop cancer. Quite separate from the challenge of estimating survival accurately, physicians may also find the process of disclosing the prognosis to their patients difficult. Using the vignette of a real patient with advanced cancer who far outlived her physician's prognostic estimate, we discuss clinical issues related to the science of prognosis in advanced cancer and the art of its disclosure. JAMA. 2003;290:98-104 www.jama.com

Ms M and Dr D were interviewed by a Perspectives editor in June 2002, some 33 months after the 3-month prognosis was delivered.

\section{PERSPECTIVES}

DR D: Ms M was first admitted with a bowel obstruction and it became apparent that she had metastatic cancer. I'd suspected this at a previous visit because of some skin lesions. What I told her at the time was that I thought [her life-expectancy] was on the order of months. The pathologists were telling me that it was probably a gastric primary, which has an even worse prognosis. I expected her to go downhill quickly.... At the time, I didn't think there was a whole lot of doubt about the prognosis, frankly.

Author Affiliations: Sections of General Internal Medicine and HematologyOncology, Department of Medicine, and the Cancer Research Center, University of Chicago, Chicago, III (Dr Lamont); Department of Health Care Policy, Harvard Medical School, and Palliative Care Service, Massachusetts General Hospital, Boston (Dr Christakis).

Corresponding Author and Reprints: Elizabeth B. Lamont, MD, MS, University of Chicago Medical Center, 5841 S Maryland Ave, MC 2007, Chicago, IL 60637 (e-mail: elamont@medicine.bsd.uchicago.edu).

Perspectives on Care at the Close of Life is produced and edited the University of California, San Francisco, by Stephen J. McPhee, MD, Michael W. Rabow, MD, and Steven Z. Pantilat, MD; Amy J. Markowitz, JD, is managing editor.

Perspectives on Care at the Close of Life Section Editor: Margaret A. Winker, MD, Deputy Editor, JAMA.

C)2003 American Medical Association. All rights reserved. 
Her reaction to the news was shock and that surprised me. It was a shock to her that at the age of 83 she might die sometime, which really surprised me because at that age, most people have lost quite a few friends. ... Since I have come to know her so much better now, I realize that what I had interpreted as a shock for herself were concerns that were a lot greater than that. People depend on her. I think that she was as shocked about the news for the impact on other people, especially the woman she shares a home with, who really could not live independently without her. Looking back, I see that may have been more important.

Ms M: Of course I immediately thought of all the things I should do, to be sure that everything is in order to leave the world. I thought of that not too long after I got home [from the appointment]. Then, of course, there's the great unknown, and the great unknown hit me, too.

\section{THE SCIENCE OF PROGNOSIS}

Although physicians tend to overestimate substantially the survival of patients with advanced cancer receiving palliative care, ${ }^{1-6}$ in this vignette, Dr D substantially underestimated Ms M's survival, an event which has been shown to occur in less than $20 \%$ of patients. ${ }^{7}$

\section{What Is the Diagnosis?}

Since the science of prognosis is anchored in disease diagnosis and extent, Ms M's diagnostic ambiguity contributed to making this case extremely challenging prognostically. Her initial skin lesions had a clinical history and course apparently consistent with malignancy but had an atypical appearance on pathological examination. Pathological evaluation of the narrowed colon had the appearance of a metastasis from a gastric primary malignancy with a singlecell infiltrative pattern, but there was no clinical evidence of a gastric primary source. Finally, the patient's apparent disseminated gastric cancer responded dramatically to tamoxifen, a therapy that has not proved effective in clinical trials of estrogen receptor-positive gastric cancers. ${ }^{7}$

Another explanation for the patient's findings and course is that she may have had a different type of disseminated cancer. Lobular breast cancer is also an adenocarcinoma that expresses estrogen receptors, has a single-cell infiltrative appearance, can seed the peritoneum and infiltrate organs, and can be associated with clinically and radiographically silent primary tumors. Either way, she had a disseminated solid tumor, prompting the question whether determining the primary tumor site (eg, further diagnostic evaluations or referral to an oncologist) would change the clinical management of the patient. The answer is yes, sometimes.

Ms $\mathrm{M}$ is an example of the potential heterogeneity of advanced solid tumors, both with respect to prognosis and available therapies. Her case reminds us that not all solid tumors are the same. Using the National Cancer Institute's (NCI) Surveillance, Epidemiology, and End Results (SEER) statistical software SEER*Stat program on 9 registry public-use data sets
(1973-1999), ${ }^{8}$ we found that disseminated gastric cancer and disseminated breast cancer have very different survival curves, with the median survival from metastatic gastric cancer only 4.1 months and the median survival from metastatic breast cancer nearly 5 times as long at 18.5 months. There is also great prognostic variability between these disseminated cancers, with dramatically different interquartile ranges (IQRs): gastric 1.5 to 8.5 months vs breast 5.5 to 43.5 months. Part of the difference relates to tumor biology, but part, too, likely relates to the effective and well-tolerated therapeutic option for disseminated breast cancer (ie, hormonal therapy), which has no parallel in disseminated gastric cancer.

\section{What Are the Goals of Treatment?}

In addition to helping to predict prognosis directly, determining diagnosis informs treatment, which may also modify prognosis. Despite the significant ambiguity about her diagnosis from the time of presentation until death, Dr D provided Ms $\mathrm{M}$ with outstanding care by prescribing tamoxifen, which likely exceeded her initial therapeutic goal of palliation (ie, reducing or containing her visceral metastases to decrease likelihood of recurrent bowel obstructions) and ended up also providing her with life prolongation. Ideally, a consulting oncologist would have explicitly considered how different therapies given to palliate the patient's bowel obstruction might affect survival. For instance, such a consulting physician might first consider the average survival of all women with metastatic breast cancer as 18.5 months (SEER value includes both patients treated with anticancer therapy and those untreated). Then, they could estimate how either a clinical response to tamoxifen with tumor shrinkage or stabilization vs tumor progression might modify these averages. In this scenario, the physician might consider that, on average, similar women treated as part of the original clinical trials of tamoxifen lived approximately 24 months, with an IQR of 18 months to more than 5 years. ${ }^{9-11}$ Those patients who experience tumor shrinkage or stabilization with tamoxifen would likely fall on the longer end of the survival distribution and those patients whose tumors progressed while taking tamoxifen would tend to fall on the shorter end of the survival distribution. Thus, the consultation with an oncologist might have yielded a longer point estimate of survival (ie, 24 months) and a greater distribution of survival, 18 months to more than 5 years, depending on the response to tamoxifen and to subsequent therapies (eg, aromatase inhibitors, chemotherapy).

\section{Prognostic Consultation}

In a patient such as Ms M, with an incompletely defined illness, it is reasonable to ask, "Will further investigation change clinical management?" With respect to disseminated malignancies in frail elderly patients who might not tolerate aggressive chemotherapies, some internists might recommend against aggressive diagnostic evaluations (sometimes foregoing consultation with an oncologist) and instead recom-

(Reprinted) JAMA, July 2, 2003-Vol 290, No. 199 
mend initiating supportive care. Ms $\mathrm{M}$ is an example of why aggressive evaluations by subspecialists may be of value for some patients: (1) to enhance prognostic certainty through more refined characterization of the disease, and (2) to inform supportive care. For this patient, a more complete definition of her illness (ie, determining the primary tumor site) may have changed both what the physician told the patient about her expected survival and how the physician managed the patient's supportive care (eg, considering that tamoxifen might prolong survival, timing of a referral to hospice, identifying the types of palliative therapies).

Quite apart from the issue of greater prognostic accuracy through refinement of diagnosis and familiarity with the survival implications of possible therapies, consulting physicians (eg, oncologists, palliative medicine specialists, and others) may have enhanced prognostic accuracy relative to the referring physician by virtue of the fact that they have no prior relationship with the patient. This recommendation stems from research suggesting that physicians with less emotional attachment to patients may provide more realistic estimates of their survival ${ }^{6}$ and that prognoses averaged across several physicians are more accurate than the prognosis of a single physician. ${ }^{12,13}$ The success of this technique may relate to minimizing the importance of extreme estimates from physicians (ie, decreasing the signal-tonoise ratio), which may themselves relate to the level of physician emotional attachment to the patient. Thus, through either formal (eg, oncologic consultation, tumor boards) or informal consultation (eg, curbside consultations), physicians may find disinterested colleagues helpful in improving the accuracy of the prognostic estimates they formulate regarding their patients, and patients may wish to seek such second opinions themselves.

\section{Other Sources of Prognostic Information}

Unfortunately, there is no single, simple source of prognostic information, and finding it can often be a challenge for physicians. ${ }^{14,15}$ However, physicians may find relevant prognostic information in previously published survival curves, in medical literature examining the survival implications of patient attributes, and in their own clinical predictions about patient survival.

\section{Survival Curves}

The SEER stage-specific survival curves are available in staging manuals, ${ }^{16}$ oncologic textbooks, ${ }^{17}$ and publicly available data, ${ }^{18}$ and survival curves are routinely generated from clinical trials of anticancer therapy. Other sources of survival data are natural history studies and randomized therapy trials that include a treatment arm that consists of supportive care only and not anticancer therapy. Typically, natural history studies are single-institution case series of untreated patients with mortality follow-up and have been reported in a variety of cancers, including head and neck cancer, ${ }^{19}$ breast cancer, ${ }^{20}$ and hepatocellular cancer. ${ }^{21}$ Randomized clinical trials with a "best supportive care" arm include trials in advanced non-small cell lung cancer, ${ }^{22-25}$ hepatocellular cancer, ${ }^{26}$ metastatic colon cancer, ${ }^{27}$ 5-fluorouracil refractory stage IV colon cancer ${ }^{28}$ stage IV pancreatic cancer, ${ }^{29}$ and stage IV gastric cancer. ${ }^{30}$

\section{Performance Status}

Performance status is a global measure of a patient's functional capacity and has substantial prognostic significance. Consistently, it has been found to predict survival in cancer patients ${ }^{31}$ and it is frequently used as a selection factor for patients entering clinical trials and also as an adjustment factor in the subsequent analyses of treatment effect. Several different metrics have been developed to determine performance status. The Karnofsky performance status score is used most often. It ranges from $100 \%$, signifying normal functional status with no complaints or evidence of disease, to 0 , signifying death.

Multiple studies ${ }^{2,5,32-46}$ report that cancer patients with poorer performance status have shorter survival. Several studies report that among patients enrolled in palliative care programs, a Karnofsky performance status score of less than $50 \%$ (substantial disability) suggests a life expectancy of less than 8 weeks. $2,5,33,35,46,47$

\section{Patient Signs and Symptoms}

Clinical signs and symptoms have long been used as potential indicators of patient survival in advanced cancer. In 1966, Feinstein and others first outlined the utility of such indicators, even in preference to biological details of a patient's condition. ${ }^{48,49}$ Recently, Vigano et al ${ }^{50}$ reexamined this topic in their qualitative systematic review of prognostic factors in advanced cancer. Of 136 different variables from 22 studies, performance status was the best predictor of patient survival, followed by dyspnea, ${ }^{35,51-54}$ dysphagia, ${ }^{33,51,53,55}$ xerostomia, ${ }^{33,47,56}$ anorexia, ${ }^{33,47,56}$ and cognitive impairment. ${ }^{1-3,5,33,47,56,57}$

\section{Physicians' Clinical Predictions}

Many previous studies of prognostic accuracy for groups of patients enrolled in palliative care programs show that physicians tend to overestimate patient survival by a factor of 3 to $5 .^{1-6}$ Nonetheless, these estimates do correlate with patients' actual survival. ${ }^{5,6,50}$ This fact suggests that physicians have potentially valuable discriminatory abilities, which may be a useful source of information regarding patient survival. ${ }^{58}$ Thus, integration of clinical predictions with other known prognostic factors may be beneficial in estimating patient survival.

\section{Integrated Models}

Investigators have sought to predict patient survival more accurately by combining many of these previously identified clinical predictors. The most recent iteration of studies report integrated models that render a single prognostic score from a combination of prognostic variables. For example, Morita et $\mathrm{al}^{53}$ developed a regression model predicting survival from per-

(C)2003 American Medical Association. All rights reserved. 
formance status and specific clinical signs and symptoms termed the Palliative Prognostic Index. The investigators report that the index predicted 3-week survival with a sensitivity of $83 \%$ and a specificity of $85 \%$, and 6-week survival with a sensitivity of $79 \%$ and a specificity of $77 \%$. This model was developed in one sample of patients enrolled in palliative care and validated in a second sample.

Further research is needed to determine whether these scoring systems are useful in the clinical care of cancer patients and whether they are applicable to patients who are not yet enrolled in palliative care programs. With respect to the clinical utility of the scoring systems, treating physicians will need to determine if the test characteristics of the tools (eg, sensitivity and specificity) fall above certain minimum thresholds for use in clinical decisions. Because of the issue of "zerotime" (ie, the analytic impact of the selection of the time at which measurement of survival begins), ${ }^{48,49}$ many of the algorithms that rely on the Karnofsky performance status score, symptoms, or laboratory values obtained after referral to hospice may not be applicable to patients with advanced cancer prior to referral to hospice.

\section{THE ART OF PROGNOSTIC DISCLOSURE}

Disclosing a poor prognosis to patients is among a physician's most difficult tasks. ${ }^{12,59,60}$ Physicians must understand how critically important it is for patients to obtain information about the expected course of their illness (including their expected survival). As Ms M articulates, patients use this information in a variety of ways, including as a way to inform decisions about which medical therapies to pursue ${ }^{61-66}$ and when to put their personal affairs in order. Patients with terminal illness want their physicians to be honest about the severity of their illness, but also want physicians to be optimistic. ${ }^{64-66}$ It may be the difficulty of meeting both these seemingly disparate needs that leads some physicians to choose to communicate overly optimistic survival estimates to patients ${ }^{67}$ and thus contribute to the documented discrepancies between patients and their physicians on the matter of prognosis. ${ }^{68,69}$

\section{An Algorithm for Disclosure}

Communicating bad news about a poor prognosis can be made easier with the use of algorithms that are created to include those elements that patients say they want and need to make decisions about how they will spend their remaining time. ${ }^{61-66}$ Several groups have outlined approaches to the successful disclosure of bad news. ${ }^{70-74}$ In one approach, the physician understands the encounter to include 4 temporally ordered segments, each with its own, important communication tasks. ${ }^{73}$ Roughly paraphrased, these segments are the preparation, the content, the patient's response, and the close. The TABLE contains a summary of the types of tasks that, based on prior research of patients' information preferences in advanced cancer, ${ }^{64-66}$ we and other clinicians ${ }^{70-74}$ believe are important components of each segment.

\section{The Preparation}

Ms M: Dr D told me about the appointment and wanted me to bring significant people with me to be there, and I brought young friends and relatives. That's when we got the word. Someone asked me how I felt, and my response was that I don't want to leave all these people. I don't know how much it penetrated. . . It was something I've never experienced before. The support system being there was really a key thing.

As Dr D clearly appreciated, and Ms M recognized as crucial, in the preliminary phase of prognostic disclosure, the physician prepares for the conversation with the patient by undertaking extensive research regarding the patient's illness, expected survival, and therapeutic considerations, and ideally sets the scene to be as supportive as possible for the patient and family. Arrangements should be made for an inperson conversation without interruptions and with ample time for questions. Research suggests that cancer patients place the greatest importance on their physician being upto-date on research of the patient's particular type of cancer. They also rated highly the importance of physicians giving patients their full attention and patients having enough time to have asked and have answered all their questions. ${ }^{64}$ As is evident in the preceding passage, Dr D appreciated that such discussions between patients and their physicians are nodal points in patients' lives and deserve special focus and steadfast emotional support.

\section{The Content}

DR D: I said that the disease was far advanced and I expected that her life would be limited and I believed it was on the order of months, to give her a ballpark [figure]. It was late summer when this was diagnosed and I really didn't think that she would live until Christmas, realistically.

In this phase of prognostic disclosure, the physician discusses the patient's illness and expected prognosis. In the case of Ms M, Dr D might have discussed the ambiguity of Ms M's diagnosis and the other possibilities on the differential diagnosis list. A way to engage prognosis when the diagnosis is uncertain is to discuss survival estimates of each of the diagnoses being considered. We advocate that when communicating prognosis to patients, the physician should first anchor the estimate in an average survival for similar patients, disclosing the median survival and IQR. Then they can comment on how the patient's existing performance status, symptoms, and subsequent treatment response might modify the estimate. For example, in this situation the physician might have acknowledged to the patient that her diagnosis was unclear and thus her prognosis was unclear. She could explain that the diagnoses she was considering were stage IV gastric cancer and stage IV breast cancer and that each had very different survival horizons and likely responses to therapy. If the patient was one who appreciated greater detail, she could explain that of 100 patients with stage IV gastric cancer, the average survival is 16 weeks with $75 \%$ of patients living at least 6 
weeks and 25\% living 34 weeks or longer. ${ }^{8}$ She could then provide the same parameters for stage IV breast cancer. Although physicians report that they have mixed feelings about using survival estimates and statistics in their discussions with patients about poor prognoses, ${ }^{12}$ the technique has the clear advantage of anchoring patients in a prognostic estimate that is reasonable. With further discussion of the IQR, patients may come to understand the prognostic range and can plan accordingly.
Articulating explicitly the goals of treatment and whether the treatment has the potential of prolonging life is also critical. Dr D might have told Ms M that since it was possible that her tumor originated in the breast, it might be worth trying effective treatment for breast cancer to shrink or stabilize the tumor to prevent another bowel obstruction. If the treatment worked, which could be assessed by following the size of the skin tumors, then the bowel problems might improve, and Ms M might live longer than the aver-

Table. Four Elements of an Approach to Delivering a Prognosis

Tasks Possible Ways to Express It

\begin{tabular}{|c|c|}
\hline Tasks & Possible Ways to Express It \\
\hline \multicolumn{2}{|c|}{ Preparation } \\
\hline \multicolumn{2}{|c|}{$\begin{array}{l}\text { Research the patient's condition to determine prognostic parameters } \\
\text { with and without therapy, both "life-prolonging" and "palliative" }\end{array}$} \\
\hline \multicolumn{2}{|l|}{$\begin{array}{l}\text { Arrange meeting in private place with ample time, seating, tissues, and } \\
\text { no interruptions (eg, telephones, pagers, staff) }\end{array}$} \\
\hline $\begin{array}{l}\text { Alert the patient ahead of time that you need to discuss important } \\
\text { aspects of his or her health. Suggest that the patient bring a person } \\
\text { important in his or her life to the meeting }\end{array}$ & $\begin{array}{l}\text { "The next time we meet, we will be reviewing important test results } \\
\text { regarding your illness. I think it is important that you bring with you } \\
\text { someone who is important to you." }\end{array}$ \\
\hline $\begin{array}{l}\text { At the meeting, first establish how the patient is feeling, identifying } \\
\text { symptoms that can be the later focus of discussion of palliative } \\
\text { therapies. Establish current level of debilitation (ie, performance } \\
\text { status) }\end{array}$ & $\begin{array}{l}\text { "First, l'd like to find out how you are feeling right now." "Do you have any } \\
\text { pain or other symptoms from the illness?" "How are you spending your } \\
\text { days?" "Are you able to wash up?" "Who's doing the cooking and } \\
\text { cleaning now?" "How much of the day do you think you are in bed or } \\
\text { on the couch?" }\end{array}$ \\
\hline $\begin{array}{l}\text { Establish the patient's understanding of his or her illness. Ask what the } \\
\text { patient hopes you will be able to do }\end{array}$ & $\begin{array}{l}\text { "I wonder what your current understanding of your illness is and what you } \\
\text { hope we can do for you." }\end{array}$ \\
\hline $\begin{array}{l}\text { Finally, establish what the patient wishes to know from you about their } \\
\text { illness }\end{array}$ & $\begin{array}{l}\text { "Some people want to know everything possible about their illness and } \\
\text { others prefer to know very little. How much about your illness do you } \\
\text { want to know from me today?" }\end{array}$ \\
\hline \multicolumn{2}{|c|}{ Content } \\
\hline $\begin{array}{l}\text { Tell the patient that you have bad news to share ("Give a warning } \\
\text { shot" }{ }^{7} \text { ) }\end{array}$ & "I am sorry to say that I have bad news to share today." \\
\hline State the news clearly, simply, and sensitively & $\begin{array}{l}\text { "It appears that the cancer has spread to your bones, which means that it } \\
\text { is no longer curable." }\end{array}$ \\
\hline \multicolumn{2}{|l|}{ Provide information in small amounts at a time } \\
\hline Make optimistic statements that are truthful & "I am very hopeful that with medicine we can control your bone pain." \\
\hline $\begin{array}{l}\text { Anchor the survival estimate you communicate in previously published } \\
\text { data and modify it by the patient's current clinical status }\end{array}$ & $\begin{array}{l}\text { "On average, patients with stage IV gastric cancer live } 4 \text { months. One } \\
\text { quarter of patients will live } 1.5 \text { months or less and one quarter live } 8 \\
\text { months or more. While I do not know for sure where you are in that } \\
\text { group, the fact that you are feeling so poorly right now and in bed } \\
\text { most of the time makes me concerned that you may not live longer } \\
\text { than the average } 4 \text { months." }\end{array}$ \\
\hline \multicolumn{2}{|c|}{ Patient's Response } \\
\hline Acknowledge the patient's affect and express empathy & "I can tell how very difficult it is for you to hear this bad news." \\
\hline $\begin{array}{l}\text { Assure the patient of your continued involvement in his or her medical } \\
\text { care. Squarely address the issue that forgoing chemotherapy does } \\
\text { not create a therapeutic void; patients often conflate "doing } \\
\text { something" with chemotherapy }\end{array}$ & $\begin{array}{l}\text { "Although we cannot cure or shrink your cancer with chemotherapy, we } \\
\text { certainly can continue to take care of you and treat you with medicines } \\
\text { for any symptoms that the cancer may cause. There is always } \\
\text { something that we can do to help you." }\end{array}$ \\
\hline \multicolumn{2}{|c|}{ Close } \\
\hline $\begin{array}{l}\text { Summarize the new news sensitively and outline a short-term plan of } \\
\text { care }\end{array}$ & $\begin{array}{l}\text { "What we have discussed is that your cancer has progressed to involve } \\
\text { your bones, which has caused the calcium in your blood to become } \\
\text { dangerously high. What I recommend we do next is to focus on } \\
\text { returning the calcium level to normal and strengthening the bone } \\
\text { around the tumor by adding a new medicine that is given by vein every } \\
\text { month. I recommend that you get the first dose today in our office." }\end{array}$ \\
\hline \multicolumn{2}{|l|}{$\begin{array}{l}\text { Arrange a follow-up visit (even if the patient is being referred for hospice } \\
\text { care), since it is a tangible example of your continued commitment to } \\
\text { the patient }\end{array}$} \\
\hline \multicolumn{2}{|l|}{$\begin{array}{l}\text { Offer to discuss the news with people important to the patient who are } \\
\text { not present }\end{array}$} \\
\hline $\begin{array}{l}\text { Provide the patient with a means of contacting you or your team in an } \\
\text { emergency }\end{array}$ & \\
\hline
\end{tabular}


age time discussed. The physician could advise Ms M that patients with breast cancer whose tumors stabilize or shrink with tamoxifen likely survive longer than the average 18.5 months' survival and would likely experience at least the 24 months' survival that the patients treated in tamoxifen trials had achieved. The physician also could explain that if the treatment did not work and the tumors grew, the tumor was more likely to be of gastric origin or a less favorable breast cancer, so the survival might range from the more typical 5 months of gastric cancer to up to about 18.5 months in the event of tamoxifen-resistant breast cancer.

\section{Patient's Response}

DR D: She was very surprised and pretty shocked about having a relatively short prognosis in the beginning, and because of her age, I was surprised, that it really had never dawned on her that she needed to have her affairs in order.

Ms M: I didn't expect to hear the 3 months, no. I really didn't know what to expect.

In this phase, the physician carefully observes the patient and acknowledges the patient's affect and response after hearing the probable effects of the illness and the patient's expected survival. The patient may identify concerns to which the physician can respond to help the patient better understand the illness and how it can be managed. Making optimistic but true statements may help the patient focus on tenable goals of therapy.

\section{The Close}

Ms M: Having people understand a situation and knowing they could call her [DrD] if they wanted to, I think is a foundation of it. Maybe I'm not supposed to say it, but she's more like a friend than this person that's off somewhere else and tells you on the phone what to do.

In the final phase of prognostic disclosure, the physician summarizes the information discussed, makes a short-term plan with the patient, and as Dr D clearly conveyed, assures the patient and her support circle of the physician's continued involvement and availability. As a substantive matter, in this case, the physician might review that the patient has a tumor adherent to the bowel causing a blockage, that although its origin is not clear, it is most likely gastric cancer or breast cancer. Since these cancers have different survival patterns and different therapies, the physician explains how she and the patient will need to revisit the issue of diagnosis, treatment, and survival as they learn more about how the tumor responds to the recommended tamoxifen therapy. They make a plan to start the tamoxifen, to evaluate the size of the skin lesions on a certain date, and to revisit diagnosis, prognosis, and treatment at that time. We believe that such concrete plans, even in the therapeutic situation of purely supportive care with opioids or antipyretics, have the dual effects of focusing on improving the patient's condition and assuaging patients' fears that "nothing more can be done," and thus they will be abandoned by their physician.

\section{CONCLUSIONS}

DR D: Really the purpose of our offering a prognosis to a patient is to help them live their life the way they want to live it. ... [I don't know where] we got this idea that our being "right" about prognosis [is] tied to our abilities. ... We need to unhook the idea of prognostication from our egos and recognize that it's information that patients need. When we prognosticate and it turns out that the patient lives a longer life, then we can be joyous with them, but when we prognosticate and the patient ends up living a far shorter time, that's when we really do harm.

As described by Dr D, physicians may have the opportunity to improve their patients' end-of-life experiences by simply helping them to understand the life-limiting nature of their illness and defining their expected survival. As illustrated by the case of Ms M, patients often want to accomplish certain things before dying, and comprehending that remaining time is short may prompt them to do those things. Such efforts should be regarded as at least as important as the fundamental therapeutic tasks of pain and symptom management and may well be as professionally rewarding. Thus, prognosis deserves prominence in the care of patients with life-threatening diseases like advanced cancer, and continued research on the science of prognosis and the art of its disclosure is needed.

Funding/Support: The Perspectives on Care at the Close of Life section is made possible by a grant from the Robert Wood Johnson Foundation. This work was funded by grant K07 CA-93892 from the National Institutes of Health (Dr Lamont). Other Resources: For a list of relevant Web sites, see the article on the JAMA Web site at http://www.jama.com

Acknowledgment: We thank Gini Fleming, MD, of the University of Chicago Breast Oncology Program for her critical review of the manuscript.

\section{REFERENCES}

1. Parkes EM. Accuracy of predictions of survival in later stages of cancer. BMJ. 1972;2:29-31.

2. Evans $C, M c C$ arthy $M$. Prognostic uncertainty in terminal care: can the Karnofsky index help? Lancet. 1985;1:1204-1206.

3. Heyse-Moore LH, Johnson-Bell VE. Can doctors accurately predict the life expectancy of patients with terminal cancer? Palliat Med. 1987;1:165-166.

4. Forster LE, Lynn J. Predicting life span for applicants to inpatient hospice. Arch Intern Med. 1988;148:2540-2543.

5. Maltoni M, Nanni O, Derni S, et al. Clinical prediction of survival is more accurate than the Karnofsky performance status in estimating life span of terminally ill cancer patients. Eur J Cancer. 1994;30A:764-766.

6. Christakis NA, Lamont EB. Extent and determinants of error in doctors' prognoses in terminally ill patients: prospective cohort study. BMJ. 2000;320:469473 .

7. Harrison JD, Morris DL, Ellis IO, et al. The effect of tamoxifen and estrogen receptor status on survival in gastric cancer. Cancer. 1989;64:1007-1010.

8. Surveillance Research Program, National Cancer Institute SEER*Stat Software. Version 4.2. Available at: http://www.seer.cancer.gov/seerstat. Access verified June 12, 2003.

9. Taylor SG, Gelman RS, Falkson G, et al. Combination chemotherapy compared to tamoxifen as initial therapy for stage IV breast cancer in elderly women Ann Intern Med. 1986;104:455-461.

10. Gockerman JP, Spremulli EN, Raney M, et al. Randomized comparison of tamoxifen versus diethylstilbestrol in estrogen-receptor-positive or unknown metastatic breast cancer: a Southeastern Cancer Study Group Trial. Cancer Treat Rep. 1986:70:1199-1203.

11. Peethambaram PP, Ingle JN, Suman VJ, et al. Randomized trial of diethylstillbestro vs tamoxifen in postmenopausal women with metastatic breast cancer: an updated analysis. Breast Cancer Res Treat. 1999;54:117-122.

12. Christakis NA. Death Foretold: Prophecy and Prognosis and Medical Care. Chicago, Ill: University of Chicago Press; 1999.

(Reprinted) JAMA, July 2, 2003-Vol 290, No. 1 103 
13. Poses RM, Bekes C, Winkler RL, Scott WE, Copare FJ. Are two (inexperienced) heads better than one (experienced) head? Arch Intern Med. 1990;150: 1874-1878.

14. Lamont EB, Christakis NA. Prognostication in advanced disease. In: Berger A Portenoy RK, Weissman DE, eds. Principles and Practice of Palliative Care and Supportive Oncology. 2nd ed. Philadelphia, Pa: Lippincott Williams \& Wilkins; 2002 15. Glare $P$, Christakis N. Predicting survival in patients with advanced cancer. In Doyle D, Hanks GWC, MacDonald N, eds. Oxford Textbook of Palliative Medicine. 3rd ed: New York, NY: Oxford University Press. In press.

16. American Joint Commission on Cancer. Handbook for Staging of Cancer. Philadephia, Pa: Lippincott; 1992.

17. DeVita VT, Hellman S, Rosenberg SA, eds. Cancer: Principles and Practice of Oncology. 4th ed. Philadelphia, Pa: Lippincott Williams \& Wilkins; 1993.

18. Surveillance Epidemiology and End Results. Available at: http://seer.cance .gov. Accessed June 6, 2003.

19. Kowalski LP, Carvalho AL. Natural history of untreated head and neck cancer. Eur J Cancer. 2000;36:1032-1037

20. Johnstone PA, Norton MS, Riffenburgh RH. Survival of patients with untreated breast cancer. J Surg Oncol. 2000;73:273-277.

21. Attali P, Prod'homme S, Pelletier G, et al. Prognostic factors in patients with hepatocellular carcinoma. Cancer. 1987;59:2108-2111.

22. Cellerino R, Tummarello D, Guidi $F$, et al. A randomized trial of alternating chemotherapy versus best supportive care in advanced non-small cell lung cancer. J Clin Oncol. 1991;8:1453-1461.

23. Anderson H, Hopwood P, Stephens RJ, et al. Gemcitabine plus best supportive care (BSC) vs BSC in inoperable non-small cell lung cancer: a randomized trial with quality of life as the primary outcome. Br J Cancer. 2000:83:447-453.

24. Roszkowski K, Pluzanska A, Krzakowski M, et al. A multicenter, randomized phase III study of docetaxel plus best supportive care versus best supportive care in chemotherapy-naive patients with metastatic or non-resectable localized nonsmall cell lung cancer. Lung Cancer. 2000;27:145-157.

25. Thongprasert $S$, Sanguanmitra $P$, Juthapan $W$, et al. Relationship between quality of life and clinical outcomes in advanced non-small cell lung cancer: best supportive care (BSC) versus best supportive care plus chemotherapy. Lung Cancer. $1999 ; 24: 17-24$

26. CLIP Group. Tamoxifen in treatment of hepatocellular carcinoma: a randomised controlled trial. Lancet. 1998:352:17-20.

27. Scheithauer W, Rosen H, Krnek GV, et al. Randomised comparison of combination chemotherapy plus supportive care with supportive care alone in patients with metastatic colorectal cancer. BMJ. 1993;306:752-755.

28. Cunningham D, Glimelius B. A phase III study of irinotecan (CPT-11) versus best supportive care in patients with metastatic colorectal cancer who have failed 5-fluorouracil therapy: V301 Study Group. Semin Oncol. 1999;26(suppl 5):6-12 29. Keating JJ, Johnson PJ, Cochrane AM, et al. A prospective randomized trial of tamoxifen and cyproterone acetate in pancreatic carcinoma. Br J Cancer. 1989; 60:789-792.

30. Glimelius B, Ekstrom K, Hoffman K, et al. Randomized comparison between chemotherapy plus best supportive care with best supportive care in advanced gastric cancer. Ann Oncol. 1997;8:163-168.

31. Zubrod GC, Schneiderman M, Frei E, et al. Appraisal of methods for the study of chemotherapy in man: comparative therapeutic trial of nitrogen and mustard and triethylene thiophosphoramide. J Chron Dis. 1960;11:7-33.

32. Janisch L, Mick R, Schilsky RL, et al. Prognostic factors for survival in patients treated in phase I clinical trials. Cancer. 1994;74:1965-1973.

33. Maltoni M, Pirovano M, Scarpi E, et al. Prediction of survival for patients terminally ill with cancer. Cancer. 1995;75:2613-2622.

34. Christakis NA. Timing of referral of terminally ill patients to an outpatient hospice. J Gen Intern Med. 1994;9:314-320.

35. Reuben DB, Mor V, Hiris J. Clinical symptoms and length of survival in patients with terminal cancer. Arch Intern Med. 1988;148:1586-1591.

36. Coates A, Porzsolt F, Osoba D. Quality of life in oncology practice: prognostic value of EORTC QLQ-C30 scores in patients with advanced malignancy. Eur J Cancer. 1997:33:1025-1030.

37. Allard P, Dionne A, Potvin D. Factors associated with length of survival among 1081 terminally ill cancer patients. J Palliat Care. 1995;11:20-24

38. Rosenthal MA, Gebski VJ, Kefford RF, et al. Prediction of life-expectancy in hospice patients: identification of novel prognostic factors. Palliat Med. 1993;7 199-204.

39. Loprinzi CL, Laurie JA, Wieand $S$, et al. Prospective evaluation of prognostic variables from patient-completed questionnaires. J Clin Oncol. 1994;12:601-607.

40. Yates JW, Chalmer B, McKegney P. Evaluation of patients with advanced cancer using the Karnofsky performance status. Cancer. 1980;45:2220-2224.

41. Mor V, Laliberte L, Morris JN, et al. The Karnofsky performance status scale. Cancer. 1984;53:2002-2007.

42. Hyde L, Wolf J, McCracken S, et al. Natural course of inoperable lung cancer. Chest. 1973;64:309-312
43. McCusker J. The terminal period of cancer: definition and descriptive epidemiology. J Chronic Dis. 1984;37:377-385.

44. Shimozuma K, Sonoo $H$, Ichihara K, et al. The prognostic value of quality-oflife scores: preliminary results of an analysis of patients with breast cancer. Surg Today. 2000;30:255-261.

45. Pirovano $M$, Maltoni $M$, Nanni $O$, et al. A new palliative prognostic score: a first step for the staging of terminally ill cancer patients. J Pain Symptom Manage. 1999;17:231-239.

46. Morita T, Tsundoa J, Inoue $S$, et al. Validity of the palliative performance scale from a survival perspective. J Pain Symptom Manage. 1999;18:2-3.

47. Llobera J, Esteva M, Rifa J, et al. Terminal cancer: duration and prediction of survival time. Eur J Cancer. 2000;36:2036-2043.

48. Feinstein AR. Clinical Judgement. Baltimore, Md: Williams \& Wilkins; 1967 49. Feinstein AR, Pritchett JA, Schimpff CR. The epidemiology of cancer therapy. Arch Intern Med. 1969;123:232-344.

50. Vigano A, Dorgan $M$, Bruera $E$, et al. The relative accuracy of the clinical estimation of the duration of life for patients with end of life cancer. Cancer. 1999; 86:170-176.

51. Reuben DB, Mor V, Hiris J. Clinical symptoms and length of survival in patients with terminal cancer. Arch Intern Med. 1988:148:1586-1591.

52. Pirovano $M$, Maltoni $M$, Nanni $O$, et al. A new palliative prognostic score: a first step for the staging of terminally ill cancer patients. J Pain Symptom Manage. 1999; 17:231-239.

53. Morita T, Tsundoa J, Inoue S, et al. The Palliative Prognostic Index: a scoring system for survival prediction of terminally ill cancer patients. Support Care Cancer. 1999;7:128-133.

54. Hardy JR, Turner R, Saunders $M$, et al. Prediction of survival in a hospitalbased continuing care unit. Eur J Cancer. 1994;30A:284-288.

55. Bruera E, Miller MJ, Kuehn N, MacEachern T, Hanson J. Estimate of survival of patients admitted to a palliative care unit: a prospective study. J Pain Symptom Manage. 1992;7:82-86.

56. Tamburini $M$, Brunelli $C$, Rosso $S$, et al. Prognostic value of quality of life scores in terminal cancer patients. J Pain Symptom Manage. 1996;11:32-41.

57. Maltoni $M$, Pirovano M, Nanni O, et al. Biological indices predictive of survival in 519 Italian terminally ill cancer patients. J Pain Symptom Manage. 1997; 13:1-9.

58. Justice AC, Covinsky KE, Berlin JA. Assessing the generalizability of prognostic information. Ann Intern Med. 1999;130:515-524.

59. Christakis NA, Iwashyna TJ. Attitude and self-reported practice regarding prognostication in a national sample of internists. Arch Intern Med. 1998;158:2389239.

60. Baile WF, Lenzi R, Parker PA, Buckman R, Cohen L. Oncologists' attitudes toward and practices in giving bad news: an exploratory study. J Clin Oncol. 2002 20:2189-2196

61. Degner LF, Kristjanson LJ, Bowman D, et al. Information needs and decisional preferences in women with breast cancer. JAMA. 1997;277:14851492.

62. Davison BJ, Degner LF, Morgan TR. Information and decision-making preferences of men with prostate cancer. Oncol Nurs Forum. 1995;22:1401-1408.

63. Blanchard CG, Labrecque MS, Ruckdeschel JC, Blanchard EB. Information and decision-making preferences of hospitalized adult cancer patients. Soc Sci Med. 1988;27:1139-1145

64. Wenrich MD, Curtis JR, Shannon SE, et al. Communicating with dying patients within the spectrum of medical care for terminal diagnosis to death. Arch Intern Med. 2001:161:868-874.

65. Parker PA, Baile WF, de Moor C, et al. Breaking bad news about cancer: patient's preferences for communication. J Clin Oncol. 2001;19:2049-2056. 66. Kutner JS, Steiner JF, Corbett KK, Jahnigen DW, Barton P. Information needs in terminal illness. Soc Sci Med. 1999;48:1341-1352.

67. Lamont EB, Christakis NA. Prognostic disclosure to patients with cancer near the end of life. Ann Intern Med. 2001;134:1096-1105

68. Mackillop WJ, Stewart WE, Ginsburg AD, Stewart SS. Cancer patients' perceptions of their disease and its treatment. Br J Cancer. 1988:58:355-359.

69. Eidinger RN, Schapira DV. Cancer patients' insight into their treatment, prognosis, and unconventional therapies. Cancer. 1984;53:2736-2740.

70. Ptacek JT, Eberhardt TL. Breaking bad news: a review of the literature. JAMA. 1996:276:496-502.

71. Buckman R. How to Break Bad News-A Guide for Health Care Professionals. Baltimore, Md: Johns Hopkins University Press; 1992.

72. Von Gunten CF, Ferris FD, Emanuel LL. Ensuring competency in end-of-life care: communication and relational skills. JAMA. 2000;284:3051-3057.

73. Fischer GS, Tulsky JA, Arnold RM. Communicating a poor prognosis. In: Portenoy RK, Bruera E, eds. Topics in Palliative Care. Vol 4. New York, NY: Oxford University Press; 2000

74. Rabow MW, McPhee SJ. Beyond breaking bad news: how to help patients who suffer. West J Med. 1999;171:260-263. 


\section{OTHER SOURCES}

\section{Education for Physicians in End-of-Life Care}

http://www.epec.net/

This is the Web site for the Education for Physicians in End-of-Life Care (EPEC) project, which contains materials (eg, teaching modules, handouts, slides) that promote physician education in care at the end of life.

http://www.eperc.mcw.edu/

The End-of-Life/Palliative Education Resource Center (EPERC) Web site contains a comprehensive catalogue of peerreviewed training materials.

\section{Clinical Care}

http://www.curriculum.som.vcu.edu/medicine/endoflife/Overview.html

Designed for Medical College of Virginia third-year medical students, this Web site is a rich resource for any physician who cares for patients near the end of life.

http://www.mgh.harvard.edu/palliativecare/

The Web site for the Massachusetts General Hospital's Palliative Care Service that provides clinical care and academic fellowship training.

http://seer.cancer.gov/seerstat/

This Web site contains information about SEER*Stat, a publicly available software program that allows users to view records for specific types of cancer and to produce population estimates, including survival estimates of medians, means, and interquartile ranges.

\section{Funding}

http://www.soros.org/death/funding.htm

This Web site describes funding opportunities in the area of care at the end of life available through the Soros Foundation.

\section{Policy}

http://www.abcd-caring.org/mainpage.htm

The Americans for Better Care of the Dying (ABCD) is a policy-oriented organization that is working to ensure that all Americans can count on good end-of-life care.

\section{Research}

http://oto.wustl.edu/clinepi/prog.html

This Web site describes a group from Washington University, St Louis, and its current research in prognostication in cancer and contains a link to an interactive prognostic tool for clinicians called the "prognostigram." 